\title{
Erythroderma as A Paraneoplastic Cutaneous Disorder in Systemic Lymphoma
}

\author{
Kaoutar Laamari*, Hanane Baybay, Samia Mrabat, Zakia Douhi, Sara Elloudi and Fatima Zahra Mernissi \\ Department of Dermatology, University Hospital Hassan II, Morocco
}

*Corresponding author: Kaoutar Laamari, Departement of Dermatology, University Hospital Hassan II, Fes, Morocco

\section{Introduction}

Pruritus and erythroderma could be a presenting sign of numerous internal malignancies. These symptoms can occur in the early stages of internal malignancies or precede them by months. On the other hand, these symptoms can also be caused by various other common conditions; therefore, they are not specific for paraneoplastic diseases. We report the case of systemic anaplastic large cell lymphoma accompanied by erythroderma.

\section{Case Report}

It was a 74 year old patient with a history of anaplastic lymphoma in remission for one year, who has had erythroderma for
4 months for which he consulted with several doctors and was put on dermocorticoids with good progress and relapse. Dermatological examination: presence of erythroderma in regression in the body with persistence of an erythematous background and presence of scaling in the face (Figure 1). On examination of the ganglionic areas: presence of multiple centimetric lymphadenopathy at fixed axillary and inguinal level, without inflammatory signs. The patient was referred to the internal medicine department where a relapse of his lymphoma was confirmed. The patient started chemotherapy 1 month ago.

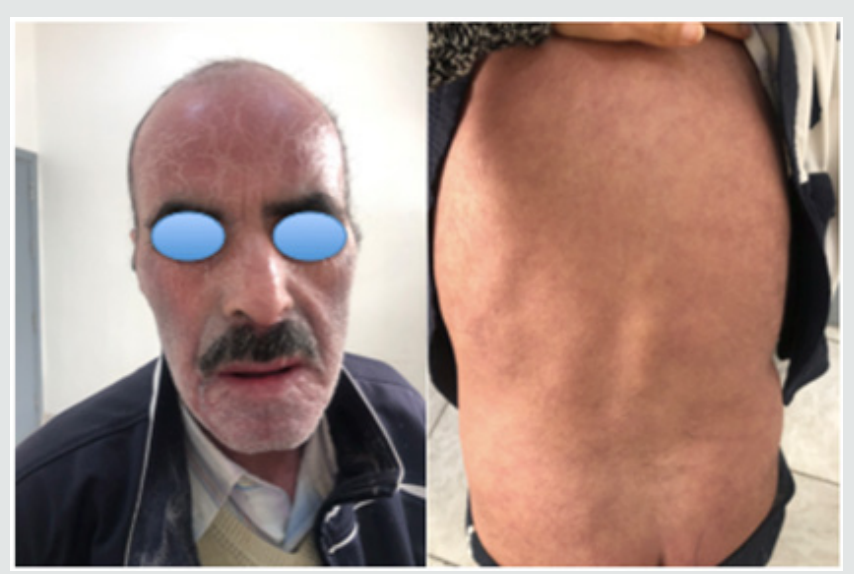

Figure 1: Presence of erythroderma in regression in the body with persistence of an erythematous background and presence of scaling in the face.

\section{Discussion}

Paraneoplastic cutaneous disorders (PCDs) or dermadromes are skin conditions that have an association with internal malignancies but are not themselves malignant. Several cases of dermatomyositis, bullous dermatosis, erythroderma, prurigo, lichen planus and porokeratosis are considered PCDs. The most important point is that no malignant cells infiltrate into the skin lesions of PCDs [1-3]. The phenomenon of a paraneoplastic dermatosis was first described by Hebra [4] in 1868 when he suggested that pigmentation of the skin could indicate underlying malignancy [5]. Erythroderma as a PCD has been linked to malignancies such as mycosis fungoides or its leukaemic variant, Sezary syndrome. Additional reported cases exist that describe erythroderma associated with cancers 
of the liver, lung, colon, stomach, pancreas, thyroid, prostate and cervix [2]. The mechanism behind paraneoplastic dermatoses is still largely unknown. It is thought that the skin changes are due to either an immunologic reaction to the tumor antigen directly or indirectly as a result of inflammatory cytokines produced by the tumor. Paraneoplastic erythroderma is more agressive and resistant to standart treatment modalities. Weakness, and significant weight loss are frequently seen as additional findings. It can be associated with fine scaling and hyperpigmentation (melanoerythroderma). Erythroderma manifests as widespread erythema accompanied by a variable degree of scaling, typically involving over $90 \%$ of the body surface area [6]. It is most commonly caused by atopic dermatitis, psoriasis as well as hypersensitivity reactions to drugs. Cases of erythroderma associated with malignancy tend to be presented as Sezary syndrome which is a type of cutaneous T cell lymphoma. Less commonly, paraneoplastic erythroderma is associated with acute myeloid leukaemia and solid tumours [7,8]. Paraneoplastic erythroderma associated with systemic lymphoma is exceptionally rare.

\section{Conclusion}

Paraneoplastic dermatoses can be the initial presentations of systemic lymphoma. Knowledge about this association may help with timely diagnosis. In a patient with unexplained dermatosis, an investigation for systemic lymphoma is warranted.

\section{References}

1. Rook A, Burns T (2010) Rook's Textbook of Dermatology ( $8^{\text {th }}$ edn.), Wiley Blackwell Chichester West Sussex UK Hoboken NJ USA.

2. Motoori M, Tsujinaka T, Kobayashi K, Fujitani K, Kikkawa N (2001) Synchronous rectal and esophageal cancer associated with prurigo chronica multiformis: report of a case Surg Today 31: 1087-1090.

3. Umekoji A, Tsuruta D, Inoue T, Nishimori T, Ishii M (2010) Bullous pemphigoid as a dermadrome associated with spindle cell carcinoma of the gallbladder. J Dermatol 37(3): 251-254.

4. Hebra F (2008) On Diseases of the Skin, Including the Exanthemata. London New Sydenham Society 1866-1880.

5. Sneddon IB (1970) Cutaneous manifestations of visceral malignancy. Postgrad Med J 46:678-685.

6. Akhyani M, Ghodsi ZS, Toosi S (2005) Erythroderma: a clinical study of 97 cases. BMC Dermatol 9(5):5.

7. Nicolis GD, Helwig EB, dermatitis E (1973) A clinicopathologic study of 135 cases. Arch Dermatol 108(6): 788-797.

8. Tagami (2016) Paraneoplastic Dermatosis in a Patient with Anaplastic Large Cell Lymphoma: Case Report and Literature Review. Dermatopathology 3: 39-43.

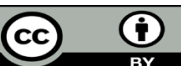

This work is licensed under Creative Commons Attribution 4.0 License

To Submit Your Article Click Here:

Submit Article
DOI: $10.32474 /$ RRHOAJ.2020.05.000203

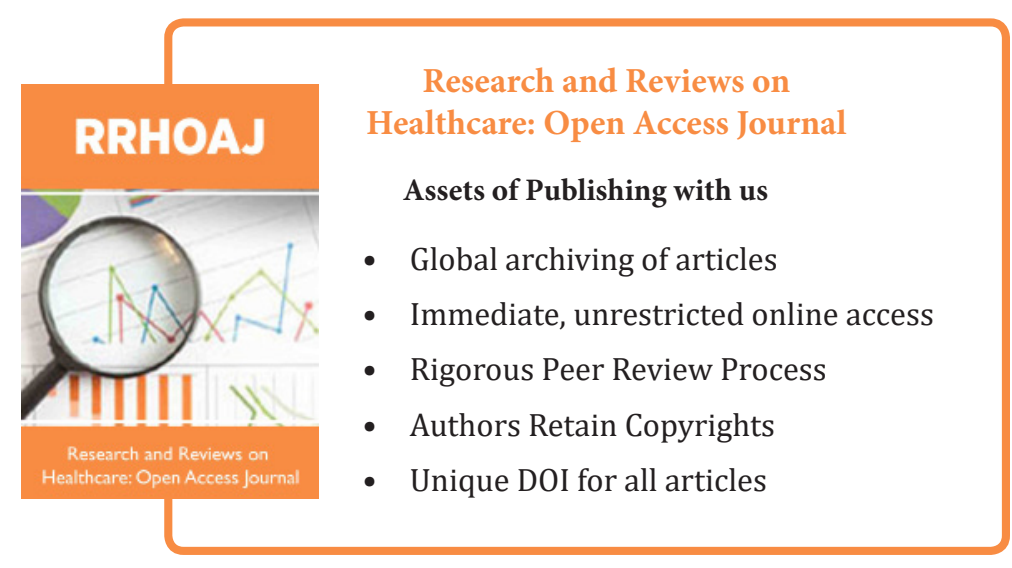

